\title{
Potential repellent activity of the essential oil of Ruta chalepensis (Linnaeus) from Chile against Aegorhinus superciliosus (Guérin) (Coleoptera: Curculionidae).
}

\author{
J. Tampe ${ }^{1,2,}$, L. Parra ${ }^{1}$, K. Huaiquil ${ }^{1}$ and A. Quiroz ${ }^{1 *}$ \\ ${ }^{1}$ Laboratorio de Química Ecológica, Departamento de Ciencias Químicas y Recursos Naturales, Universidad \\ de La Frontera, Temuco, Chile. \\ ${ }^{2}$ Programa de Doctorado en Ciencias de Recursos Naturales, Universidad de La Frontera, Temuco, \\ Chile. *Corresponding author: andres.quiroz@ufrontera.cl
}

\begin{abstract}
The objective of this study was to evaluate the repellent effect of the essential oil of the rue (Ruta chalepensis) against the weevil Aegorhinus superciliosus, an important pest of fruit crops in Chile. Rue essential oil was obtained by steam distillation, and its components were identified by GC-MS. Their effect on adult $A$. superciliosus insects was evaluated using four-arm olfactometric bioassays. The extraction process had a yield of $0.3 \%$ on a dry weight basis, and a chromatographic analysis showed the presence of nine compounds, which represented $89.3 \%$ of the total components. The major compounds were 2-nonanone $(41.7 \%)$ and 2-undecanone (40.1\%). Behavioral bioassays showed that the rue essential oil elicited a repellent effect against male and female A. superciliosus $(p \leq 0.05)$ at a concentration of $1.92 \times 10^{7} \mathrm{ng} / \mathrm{cm}^{2}$. However, at a lower concentration of the oil $\left(285.7 \mathrm{ng} / \mathrm{cm}^{2}\right)$, only females were repelled $(p \leq 0.05)$. The repellency observed against $A$. superciliosus could be attributed to high concentrations of both ketones, suggesting that rue essential oil can be considered as a potential repellent that could reduce the infestation of this weevil. The role of the compounds identified and the repellent activity of this evergreen shrub are discussed.
\end{abstract}

Keywords: Essential oil, Ruta chalepensis, Aegorhinus superciliosus

\section{Introduction}

Ruta chalepensis (Rue) is an aromatic evergreen shrub that belongs to the family Rutaceae. It is native to the Mediterranean and is currently distributed worldwide (Akkari et al., 2015). In Chile, it is traditionally cultivated for its pharmacological uses; infusions of its fresh leaves are widely used as treatment for gastric disorders, headache and rheumatism, as well as for their diuretic, anti-inflammatory and anti-spasmodic properties. Analysis of the chemical composition of $R$. chalepensis extracts indicates that the leaves and stems contain alkaloids, phenols, flavonoids, 
amino acids, saponins and furocoumarins, some of which are responsible for the reported activities (Kacem et al., 2015). Furthermore, rue essential oil is a valuable source of active metabolites used in different industries, including cosmetics, perfumes and phytotherapy. Ketones, acyclic alkenes, monoterpenes hydrocarbons, sesquiterpenes, esters and aldehydes have been identified as the main chemical groups present in the essential oil, and the ketone 2-undecanone is a characteristic compound of the Ruta species (Haddouchi et al., 2013; Ferhat et al., 2014). These compounds are produced during secondary metabolism in the plants, and their synthesis and accumulation might vary by species (Conti et al., 2013). In addition, both intrinsic and environmental factors influence this process (Ferhat et al., 2014; Da Silva et al., 2014). Recent studies have revealed several biological properties of rue essential oil. Insecticidal activity has been the focus of great interest for the potential use of this oil as an alternative botanical pesticide (Conti et al., 2013). In fact, insecticidal effects against ticks, mosquitoes, curculionids pest of stored grain and moths (Bissinger and Roe, 2010; Majdoub et al., 2014; Akkari et al., 2015) and a repellent effect on Cydia pomonella Linnaeus (Lepidoptera: Tortricidae) and Aedes aegypti Linnaeus (Diptera: Culicidae) (Landolt et al., 1999; Tabanca et al., 2012) have been reported. Therefore, the bioactivity of rue essential oil would be useful for controlling pests of economic importance, such as the raspberry weevil, in our country.

In Chile, Aegorhinus superciliosus or the raspberry weevil is a native insect and one of the most important pests of fruit crops, such as the European hazelnut (Corylus avellana) (Fagales: Betulaceae), blueberries (Vaccinium corymbosum) (Ericales: Ericaceae) and raspberries (Rubus idaeus) (Rosales: Rosaceae) (Aguilera et al., 2011). This polyphagous insect begins to colonize the host plant when female adults oviposit near the neck of a tree. Neonate larvae move to the radical zone to feed and continue their development within this zone, while the adult weevil feeds on seasonal leaves and shoots. Currently, the widespread use of synthetic insecticides, especially organophosphates and carbamates, has not been able to prevent the damage caused by this pest. Because the application of insecticides is associated with many problems, such as high cost, residues on harvested fruit, environmental degradation and resistance development (Parra et al., 2009), there is growing interest in the search for new control alternatives. In this context, natural products as well as essential oils can be alternatives for pest control because they contain bioactive substances that have low toxicity and a lesser impact on human health and the environment (Regnault-Roger et al., 2012). Currently, no reports about the repellent effect of the rue essential oil in this curculionid exist. However, there is evidence that show the insecticidal potential of the essential oil of Drimys winteri on adult A. superciliosus (Rebolledo et al., 2012), indicating that essential oils can be effective alternatives for the control of these insects. Therefore, the main objective of this study was to evaluate the repellent efficacy of the $R$. chalepensis essential oil against $A$. superciliosus.

\section{Materials and Methods}

\subsection{Plant material and essential oil isolation procedure}

The aerial parts of the rue plant were collected during the flowering stage (October 2012) from an experimental field located at the commune of Puerto Montt (4128' South, 72 $57^{\circ}$ ' West) Región de Los Lagos, Chile. The plant identity was confirmed 
by a comparison of macroscopic and microscopic morphological characteristics to Flora de Chile and specimens in the Herbarium of the Universidad de Concepción (CONC), Chile. The extraction process for the rue essential oil followed the methodology described by Meccia et al. (2009). A sample of 1298 g containing rue leaves, stems and flowers was cut into small pieces and air-dried at room temperature for six days and then oven-dried for $24 \mathrm{~h}$ at $20^{\circ} \mathrm{C}$. A $250 \mathrm{~g}$ dry matter sub-sample was subjected to steam distillation in a Clevenger-type apparatus with 500 $\mathrm{mL}$ distilled water for $4 \mathrm{~h}$. The oil was dried over sodium sulphate and stored at $4{ }^{\circ} \mathrm{C}$ in an amber bottle prior to chromatographic analysis.

\subsection{Analysis of volatile compounds by GC-MS}

Volatile compounds ( $1 \mu \mathrm{L})$ of $R$. chalepensis essential oil dissolved in dichloromethane (HPLC grade, Sigma Aldrich, Steinheim, Germany) were injected at a concentration of $1 \mu \mathrm{g} / \mu \mathrm{L}$ into a gas chromatograph (Focus GC; Thermo Electron Corporation) coupled to a mass spectrometer (DSQ; Thermo Electron Corporation). The capillary column was BP-1 (30 $\mathrm{m} \times 0.22 \mathrm{~mm} \times 0.25 \mu \mathrm{m})$ and used helium as the carrier gas at a flow rate of $1.5 \mathrm{~mL} / \mathrm{min}$. The injector and interface were operated at $250{ }^{\circ} \mathrm{C}$ by setting the detector temperature at $200{ }^{\circ} \mathrm{C}$, with an electron impact ionization of $70 \mathrm{eV}$. The initial oven temperature was programmed to $40^{\circ} \mathrm{C}$ for $5 \mathrm{~min}$ and increased $\left(5{ }^{\circ} \mathrm{C} / \mathrm{min}\right)$ until $280{ }^{\circ} \mathrm{C}$ was reached. Mass spectroscopy was performed in a mass range from 30 to $350 \mathrm{~m} / \mathrm{z}$. Component identification was performed by searching a library (Mass Spectral Library Version 2.0) of mass spectra using a matching algorithm with a reverse search technique and by the injection of an alkene series $\left(\mathrm{C}_{9}-\mathrm{C}_{26}\right)$ that was used as a reference for calculating the Kovats indices (KI). Experimental KI were compared with the theoretical KI of compounds reported in the NIST database (NIST ver. 2.0, Thermo), as described in Tampe et al. (2015).

\subsection{Insects}

Aegorhinus superciliosus adults were manually collected between November 2012 and February 2013 from a blueberry plantation in the commune of Collipulli (37 $50^{\circ}$ 'South, $72^{\circ} 08^{\prime}$ 'West), La Araucanía, Chile. Both sexes of $A$. superciliosus were collected at least one month before being used in the olfactometric bioassays. During that time period, the insects were acclimated and maintained under laboratory conditions. They were fed blueberry leaves and shoots and distilled water, and the photoperiod was a $16 \mathrm{~h}$ photophase at $20^{\circ} \mathrm{C}$. Twenty-four hours before each bioassay, the insects were separately maintained in individual Petri dishes ( $5 \mathrm{~cm}$ i.d and $2 \mathrm{~cm}$ height) according their sex and deprived of food. The methodology used to identify the sex of the insects, consisted of examining the femur length of the third pair of legs; if this length exceeds the posterior suture of the fourth sternite, the insect is male, and if it does not, the insect is female (Reyes, 1993). Then, the insects were observed for 10 minutes, and those that were active and walking were selected for the olfactometric assays. A different individual was used in each separate experimental replicate (Parra et al., 2009).

\subsection{Olfactometric bioassay}

The olfactometric bioassays were performed in a four-arm olfactometer ( 40 by 40 by $2.5 \mathrm{~cm}$ ), which was described by Parra et al. (2009). The behavioral response of $A$. superciliosus to rue essential oil was studied according to the methodology described in Tampe et al. (2015), which consisted of an observation 
of the movement of each insect into the olfactometer during a 20 min period. In addition, EthoVision 3.1 software was used to determine the time the insect spent in each section of the olfactometer, which was divided into 5 areas: a central square zone where the vacuum bomb, with an air flow $(800 \mathrm{~mL} / \mathrm{min})$ that carried the volatile stimuli into the olfactometer, was connected and four zones corresponding to the arms, two of which were enriched with air containing volatile components released from the essential oil (S), and the other two contained dichloromethane (HPLC grade, Sigma Aldrich, Steinheim, Germany) as a control (C). Bioassays were performed by applying $1 \mu \mathrm{L}$ of rue essential oil on Whatman $\mathrm{N}^{\circ} 1$ filter paper $(0.5$ $\mathrm{cm}$ wide by $3.5 \mathrm{~cm}$ long) that was placed into glass tubes $(7 \mathrm{~cm}$ long $\times 1.5 \mathrm{~cm}$ i.d.) in two opposite arms of the olfactometer (S), while the two opposite arms of the olfactometer contained only paper (C). The dose used was $1.92 \times 10^{7} \mathrm{ng} / \mathrm{cm}^{2}$. To evaluate the diluted oil, $50 \mu \mathrm{L}$ of the oil diluted in $\mathrm{CH}_{2} \mathrm{Cl}_{2}$ was applied to Whatman $\mathrm{N}^{\mathrm{o}} 1$ paper filters in two opposite arm of the olfactometer (S) under the same conditions as in the previous bioassay, while the other two arms contained only dichloromethane (C). The dose used was 285.7 $\mathrm{ng} / \mathrm{cm}^{2}$ because it was previously determined as an effective repellent in behavioral bioassays in $A$. nodipennis (Tampe et al., 2015). Twenty repetitions were performed for each sex.

\subsection{Statistical analysis}

A statistical analysis was performed using Stats Direct software, version 2.7.2. The data obtained in the bioassays were expressed as the average time spent in each arm of the olfactometer \pm standard error and were compared by using a non-parametric Friedman test $(p \leq 0.05)$ followed by a Conover-Inman test.

\section{Results}

Steam distillation of the aerial parts of $R$. chalepensis yielded $0.3 \%(\mathrm{~mL} / \mathrm{g})$ of a yellowish color oil and strong odor. In the GC-MS analysis of the sample of rue essential oil, nine compounds were identified, and among them were ketones and esters (Table 1), representing $89.3 \%$ of the total components. The main constituents were the two aliphatic ketones 2-nonanone (41.7\%) and 2-undecanone (40.1\%). In addition, 7 unidentified compounds were present in the sample, representing $10.7 \%$ of the total components. The mass spectral data are shown in Table 2.

The olfactometric response of $A$. superciliosus toward rue essential oil indicated that both females and males were repelled by the essential oil $(p<0.0001)$. The average time spent by the females in the stimulus source was significantly less $(1.69 \pm 0.62 \mathrm{~min})$ than in the control $(16.47 \pm 0.7 \mathrm{~min} ; F=46.11 ; \mathrm{df}=2 ; p<$ 0.0001 ) (Figure 1A). Similar behavior was observed in males; where the male insects spent less time in the stimulus $(2.41 \pm 1.0 \mathrm{~min})$ than in the control $(16.48 \pm$ $1.0 \mathrm{~min} ; F=39.91$; $\mathrm{df}=2 ; p<0.0001$ ) (Figure 1B). In bioassays using diluted rue essential oil $\left(285.7 \mathrm{ng} / \mathrm{cm}^{2}\right.$; Figure 1C and 1D), males did not show a behavioral difference between the stimulus and the control $(p>$ $0.05)$, while females were repelled by the tested dose of oil ( $F=71.47 ; \mathrm{df}=2 ; p=0.0105)$ remaining for an average of $11.21 \pm 0.7 \mathrm{~min}$ in the control compared to $7.22 \pm 0.6 \mathrm{~min}$ in the stimulus. 


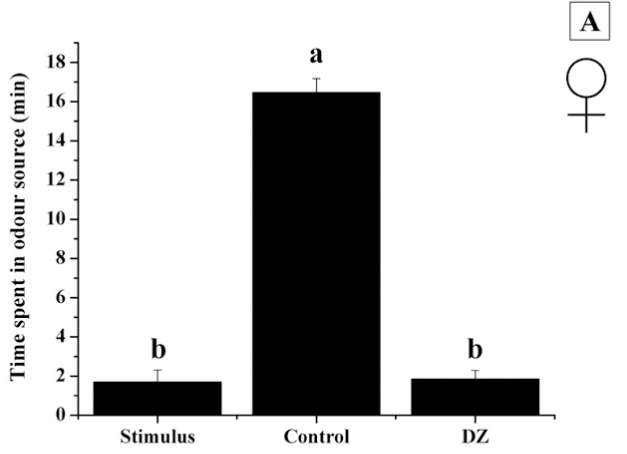

Ruta chalepensis net essential oil $\left(1.92 \times 10^{7} \mathrm{ng} / \mathrm{cm}^{2}\right)$

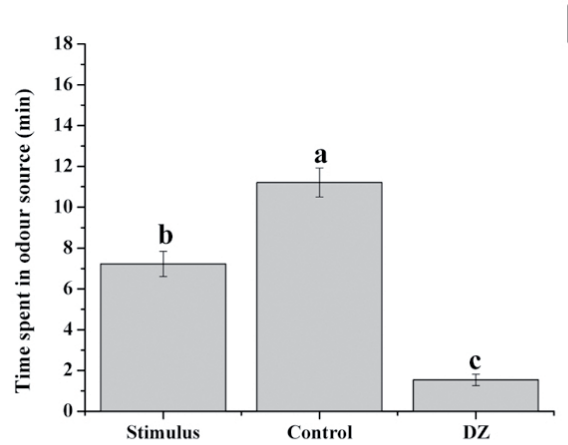

Ruta chalepensis diluted essential oil $\left(285.7 \mathrm{ng} / \mathrm{cm}^{2}\right)$
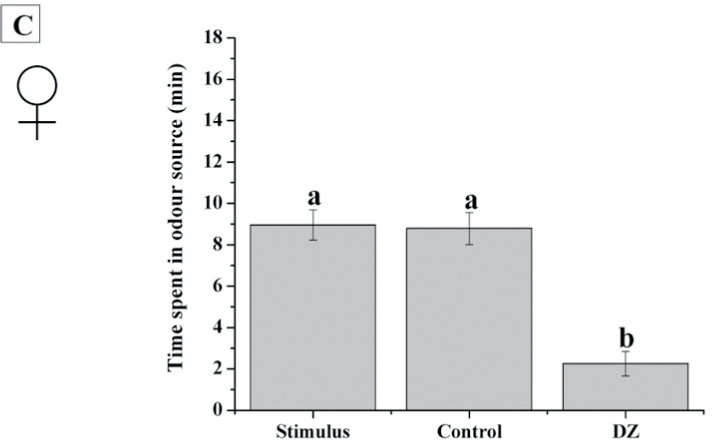

Ruta chalepensis diluted essential oil $\left(285.7 \mathrm{ng} / \mathrm{cm}^{2}\right)$

Figure 1. Average time spent (min) ( $\pm \mathrm{SE})$ of Aegorhinus superciliosus in rue essential oil $\left(1.92 \times 10^{7} \mathrm{ng} / \mathrm{cm}^{2}\right)$ (Figure A and B) and in the dilution of rue essential oil $\left(285.7 \mathrm{ng} / \mathrm{cm}^{2}\right.$ ) (Figure C and D) in the olfactometer test. Different letters indicate significant difference $(p \leq 0.05)$ based on the non-parametric Friedman test followed by Conover-Inman test. $\mathrm{S}=$ Stimulus, $\mathrm{C}=\mathrm{C}$ Control and $\mathrm{DZ}=$ Decision zone. $\mathrm{N}=20$ per sex. 
Table 1. Percentage of compounds identified in the Ruta chalepensis essential oil.

\begin{tabular}{lllc}
\hline Rt & Compound & Identification & Percentage (\%) \\
\hline 11.08 & 2-Octanone & MS, KI & 0.51 \\
$\mathbf{1 4 . 3 4}$ & 2-Nonanone & MS, KI & $\mathbf{4 1 . 7 1}$ \\
15.84 & unknown 1 & MS & 0.5 \\
16.04 & unknown 2 & MS & 2.76 \\
16.80 & unknown 3 & MS & 0.73 \\
17.27 & 2-Decanone & MS, KI & 2.18 \\
18.68 & unknown 4 & MS & 5.63 \\
$\mathbf{2 0 . 2}$ & 2-Undecanone & MS, KI & $\mathbf{4 0 . 1 1}$ \\
22.07 & 2-Dodecanone & MS, KI & 0.97 \\
25.41 & 2-Tridecanone & MS, KI & 0.91 \\
28.75 & unknown 5 & MS & 0.39 \\
35.84 & unknown 6 & MS & 0.24 \\
36.12 & Ethyl palmitate & MS, KI & 1.97 \\
39.06 & unknown 7 & MS & 0.42 \\
39.33 & Ethyl oleate & MS, KI & 0.22 \\
39.77 & Ethyl stearate & MS, KI & 0.77 \\
\hline
\end{tabular}

$\mathrm{Rt}=$ Retention time, $\mathrm{MS}=$ mass spectrum, $\mathrm{KI}=$ Kovats indices $(\mathrm{KI})$ was performed by injecting an alkenes series $\left(\mathrm{C}_{9}-\mathrm{C}_{26}\right)$. The experimental KIs were compared with theoretical KI compounds reported in the database "NIST" 
Table 2. Mass spectral data of the unknown volatile compounds from Ruta chalepensis.

\begin{tabular}{|c|c|c|c|}
\hline $\mathbf{R t}$ & Compound & $(\%)$ & $m / z$ \\
\hline 15.84 & unknown 1 & 0.5 & $\begin{array}{l}32(100), 79(30.2), 43(19.9), 94(13.9), 41(10), 51(10.0), \\
77(9.9), 39(7.7), 105(6.3), 78(5.4), 40(5.3), 91(4.2), 93(4.0), \\
31(3.5), 70(3.4) .\end{array}$ \\
\hline 16.04 & unknown 2 & 2.76 & $\begin{array}{l}79(100), 94(49.3), 77(28.0), 51(23.7), 32(18.5), 39(16.6), \\
41(15.7), 93(12.3), 105(10.9), 91(8.8), 106(7.7), 53(7.4), \\
80(6.0), 147(5.8), 120(5.4) .\end{array}$ \\
\hline 16.80 & unknown 3 & 0.73 & $\begin{array}{l}128(100), 32(72.3), 51(34.2), 127(16.0), 50(14.8), 129(11.0), \\
126(9.5), 102(7.0), 101(6.0), 75(5.3), 64(4.6), 74(3.8), \\
40(3.79), 77(3.6), 76(3.4) .\end{array}$ \\
\hline 18.68 & unknown 4 & 5.63 & $\begin{array}{l}43(100), 41(16.2), 70(12.6), 55(11.5), 126(11.4), 69(10.8), \\
97(10.0), 87(9.4), 56(8.7), 42(7.1), 71(6.0), 98(4.6), 57(3.7), \\
84(3.7), 39(3.7) .\end{array}$ \\
\hline 28.75 & unknown 5 & 0.39 & $\begin{array}{l}157(100), \quad 115(53.1), 43(41.6), 129(21.1), 203(19.6), \\
42(17.4), 111(13.7), 130(10.4), 31(9.9), 69(8.1), 158(7.6), \\
47(7.3), 32(6.7), 45(6.6), 56(5.6) .\end{array}$ \\
\hline 35.84 & unknown 6 & 0.24 & $\begin{array}{l}55(100), 41(94.2), 69(63.2), 97(53.8), 96(40.1), 70(36.7), \\
98(35.3), 101(33.9), 95(31.2), 83(30.4), 67(29.1), 73(24.5), \\
81(23.9), 68(23.6), 43(23.4) .\end{array}$ \\
\hline 39.06 & unknown 7 & 0.42 & $\begin{array}{l}32(100), 67(17.6), 41(15.4), 95(12.4), 55(11.3), 81(10.2), \\
69(9.5), 43(9.3), 96(9.2), 68(8.6), 54(6.3), 40(5.8), 109(5.7), \\
79(5.6), 97(5.5) .\end{array}$ \\
\hline
\end{tabular}

$\mathrm{Rt}=$ Retention time, $m / z=$ mass-to-charge ratio

\section{Discussion}

Steam distillation usually produces yields less than 1\% (Regnault-Roger et al., 2012). Our essential oil yield was $0.3 \%(\mathrm{v} / \mathrm{w})$, which is in line with a report by Dob et al. (2008), who indicated that the essential oil of $R$. chalepensis obtained from Algeria by hydrodistillation had a yield of a $0.27 \%$, based on sample dry weight. On the other hand, the yield of our sample was lower than that reported by Tounsi et al. (2011), who showed an increasing trend $(0.39 \%$ to $2.46 \%$ ) of essential oil obtained from the leaves, stems, flowers and fruits of $R$. chalepensis. Similarly, Mejri et al. (2010) showed a higher yield (5.51\%) 
of $R$. chalepensis essential oil from plants growing in Tunisia and indicated that the drying process had a significant effect on the proportions of main components. The differences in the oil yield might depend on the developmental stage of the plant itself or the different organs used. Some examples have demonstrated that the net essential oil content has been associated with the early growth period in a plant or with senescence (Sangwan et al., 2001). Our plant sample could have been extracted during a period of low accumulation of oil, which would explain the observed differences. Moreover, our essential oil was obtained from pooled organs (leaves, stems and flowers), but the yield was lower than in other studies that used specific $R$. chalepensis organs (Tounsi et al., 2011). In addition, the methods employed to obtain the oil (hydro and steam distillation), together with the diverse weather conditions in the growth habitat, could influence the obtained yield (Mejri et al., 2010; Tounsi et al., 2011; Regnault-Roger et al., 2012).

Interestingly, this essential oil contained a 2-ketone series from $\mathrm{C}_{8}$ to $\mathrm{C}_{13}$ (Table 1). The essential oils from the genus Ruta are known for having two methyl2-ketones (2-nonanone and 2-undecanone) in their chemical profile; reaching $80 \%$ of the oil composition (Haddouchi et al., 2013), which is consistent with our results $(81.8 \%)$. Similarly, the ketone-type compounds identified as main constituents in our study were consistent with those reported by other authors in other species from the same genus (Dob et al., 2008; Da Silva et al., 2014), indicating that the presence of 2-undecanone does not changed with respect to the geographical area where plant grows, but its proportions vary, ranging from $28.2 \%$ to $67.8 \%$. The proportions of 2-nonanone range from $5.2 \%$ to $53.1 \%$. The nature and proportions of other constituents of our essential oil were not the same as in other reports. We identified nine compounds, with ketones and esters among them (Table 1).
These results disagree with the report by Mejri et al. (2010; 2012), who found oxygenated compounds in aerial parts of $R$. chalepensis essential oil; among them were alcohols, monoterpenes and acetates. Moreover, Tounsi et al. (2011) reported the presence of monoterpenes and fatty acids from different organs of cultivated and wild rue plants. According to Wang et al. (2005), the proportion of water used and the extraction time influences the content of oxygenated compounds in the essential oil because the water affects the oxidation or hydrolysis of these compounds. Similarly, Stashenko et al. (2000) and Mejri et al. (2012) reported that the amount of oxygenated compounds increases with the duration of hydro-distillation. However, our distillation time was higher than both of these studies (240 compared to $210 / 120 \mathrm{~min}$ ), and we did not observe the presence of these compounds. Other authors have indicated that the proportion of terpenes is influenced by the circadian rhythm, plant stage and environmental temperature. Therefore, the physiological expression of the secondary metabolism of a plant could present constant changes in some of its metabolites according to the biotic and abiotic factors to which it is subjected (Regnault-Roger et al., 2012).

The behavioral response produced by the rue essential oil on both A. superciliosus sexes (Figure 1A; 1B) indicates its potential value as a natural repellent. However, this effect was absent for males when the concentration of the oil was lowered to $285.7 \mathrm{ng} / \mathrm{cm}^{2}$ (Figure 1D). These results was not consistent with the reported by Tampe et al. (2015), who determined this concentration as effective in weevil other of the same genus Aegorhinus nodipennis (Hope) using the Achillea millefolium L. essential oil and its main constituent, thujone. Behaviorally, both males and females of A. superciliosus responded differently when subjected to volatile stimuli. Apparently, females are more sensitive than males because the 
females must find a suitable host for themselves and their offspring. Similar observations were also reported by Palma et al. (2012), who indicated that in behavioral assays, a stronger response to the volatile compounds of their host plant, red clover, was observed in Hylastinus obscurus (Coleoptera: Curculionidae) females than in males. Moreover, in agreement with our observations, Conti et al. (2013) reported that $R$. chalepensis essential oil was mainly composed of 2-nonanone (37.4\%) and 2-undecanone $(20.5 \%)$ and was an effective repellent against the hematophagous mosquito Aedes albopictus Linnaeus (Diptera: Culicidae) at an $\mathrm{RD}_{50}$ of $0.000215 \mu \mathrm{L} / \mathrm{cm}^{2}$ for skin and at an $\mathrm{RD}_{90}$ of $0.007613 \mu \mathrm{L} / \mathrm{cm}^{2}$. Similarly, $R$. graveolens essential oil and its main compound, 2-undecanone $(43.2 \% \pm 0.8)$ repelled $A$. aegypti L. at a dose of $0.187 \mathrm{mg} / \mathrm{cm}^{2}$ for the oil and $0.109 \mathrm{mg} / \mathrm{cm}^{2}$ for 2-undecanone (Tabanca et al., 2012), which indicated that $A$. superciliosus females are more susceptible to this essential oil. Other authors have determined that methyl ketones $\left(\mathrm{C}_{7}-\mathrm{C}_{15}\right)$ protected against the malaria mosquito, Anopheles gambiae Giles (Diptera: Culicidae) (Innocent et al., 2008) and that the repellent BioUD $^{\circledR}$, whose active ingredient is 2-undecanone, was at least 2-4 times more repellent than DEET ( $N, N$-Diethyl-meta-toluamide) against three species of ixodid ticks (Bissinger et al., 2009; Bissinger and Roe, 2010). On the other hand, 2-nonanone and 2-undecanone was shown to be attractive to the foreign grain beetle, Ahasverus advena (Waltl) (Coleoptera: Cucujidae) at a concentration of 59 and $131 \mathrm{ng} / \mu \mathrm{L}$, respectively (Wakefield et al., 2005) and to both sexes of the olive bark beetle Phloeotribus scarabaeoides (Bernard) (Coleoptera: Scolytidae) using $10 \mu \mathrm{L}$ of these ketones in an olfactometer bioassay (SzaumanSzumski et al., 1998). Likewise, 2-nonanone has been reported by eliciting an attractant behavioral response in the same weevil, A. superciliosus at concentrations of 10 and $100 \mu \mathrm{g} / \mathrm{mL}$ (Parra et al., 2009).
Currently, the modes of action and molecular targets of the ketones in curculionids are not well understood. However, there is evidence that the ketone, 2-undecanone can activate and inhibit the odorant receptors (ORs) of $A$. aegypti L. (Diptera: Culicidae) (Bohbot and Dickens, 2010). The ORs are located in the dendritic membrane of the olfactory sensory neurons (OSNs) of the insects. They are responsible for triggering olfactory transduction by changing the action potentials as a message sent to the brain (Kaupp, 2010). The insect repellent 2-undecanone activates and inhibits the AaOR8 and AaOR2 receptors respectively; i.e., this compound can act as an olfactory agonist or antagonist in A. aegypti, modulating receptor activity that is behaviorally expressed by different insect responses (Bohbot and Dickens, 2010). This finding suggests that the repellent effect produced by rue oil in both sexes of A. superciliosus could be attributed to 2-undecanone. The potential use of this substance can be explored in the future for developing biodegradable alternatives for synthetic pesticides against raspberry weevils.

\section{Conclusions}

In conclusion, the chemical analysis of the essential oil obtained from the aerial part of Ruta chalepensis did not show great differences to others studies reported in the literature. The ketones 2-nonanone and 2-undecanone were the main compounds identified in the oil and did not vary much with respect the geographic area where the plants grew. The repellency observed against Aegorhinus superciliosus can be attributed to high concentrations of both ketones. Our results suggest that rue essential oil can be considered as a potential repellent that might reduce the infestation of this weevil. Future studies should aim to (1) evaluate the effects of 2-nonanone and 2-undecanone in behavioral bioassays, (2) determine the electrophysiological 
response of $A$. superciliosus to these compounds and (3) evaluate the effectiveness of both the essential oil and the two ketones under field conditions.

\section{Acknowledgements}

We would like to thank to Alicia Marticorena (Biologist, Master in Botany), Department of Botany, Universidad de Concepción, Chile for the identification of the plant. Financial support for this research was supplied by CONICYT with the Doctoral thesis $\mathrm{N}^{\circ} 24121197$, the Doctoral thesis in Industry $\mathrm{N}^{\mathrm{o}}$ 781211007 and the FONDECYT 11130715.

\section{References}

Aguilera, A., Guerrero, J., Rebolledo, R. 2011. Plagas y enfermedades del avellano europeo en $\mathrm{La}$ Araucanía, Chile. Ediciones Universidad de La Frontera, Temuco, pp. 126.

Akkaria, H., Ezzineb, O., Dhahri, S., B'chir, F., Rekik, M., Hajaji, S., Aziz Darghouth, M., L a h b i b Ben Jamâa, M., Gharbi, M. 2015. Chemical composition, insecticidal and in vitro anthelmintic activities of Ruta chalepensis (Rutaceae) essential oil. Ind Crop Prod. 74, 745-751

Bissinger, B.W., Apperson, C.S., Sonenshine, D.E., Watson, D.W., Roe, R.M. 2009. Efficacy of the new repellent BioUD ${ }^{\circledR}$ against three species of ixodid ticks. Exp. Appl. Acarol. 48, 239-250.

Bissinger, B.W., Roe, R.M. 2010. Tick repellents: Past, present, and future. Pestic Biochem. Phys. 96, 63-79.

Bohbot, J.D., Dickens, J.C., 2010. Insect repellents: modulators of mosquito odorant receptor activity. PLoS ONE. 5, e12138.

Conti, B., Leonardi, M., Pistelli, L., Profeti, R., Ouerghemmi, I., Benelli, G. 2013. Larvicidal and repellent activity of essential oils from wild and cultivated Ruta chalepensis L. (Rutaceae) against Aedes albopictus Skuse (Diptera: Culicidae), an arbovirus vector. Parasitol. Res. 112, 991-999.

Da Silva, F.G. E., Da S. Mendes, F.R., Da C. Assunção, J.C., Pinheiro Santiago, G.M., Xavier Bezerra, M.A., Barbosa, F.G., Mafezolic, J., Rodrigues Rocha, R. 2014. Seasonal variation, larvicidal and nematicidal activities of the leaf essential oil of Ruta graveolens L. J Essent Oil Res. 26 (3), 204209.

Dob, T., Dahmane, D., Gauriat-Desrdy, B., Daligault, V. 2008. Volatile Constituents of the Essential Oil of Ruta chalepensis L. sub sp. Angustifolia (Pers.) P. Cout. J. Essent Oil Res. 20 (4), 306-309.

Ferhat, M., Kabouche, A., Kabouche, Z. 2014. Comparative compositions of essential oils o f three Ruta species growing in different soils. J Mater Environ. Sci. 5 (3), 735-738.

Haddouchi, F., Chaouche, T..M., Zaouali, Y., Ksouri, R., Attou, A., Benmansour, A. 2013. Chemical composition and antimicrobial activity of the essential oils from four Ruta species growing in Algeria. Food Chem. 141, 253-258.

Innocent, E., Gikonyo, N. K., Nkunya, M. H. H. 2008. Repellency property of long chain a $\mathrm{liph}$ a t i c methyl ketones against Anopheles gambiae s. s. TJHR, 10 (1), 50-54.

Kacem, M., Kacem, I., Simon, G., Ben Mansour, A., Chaabouni, S., Elfeki, A., Bouaziz, . 20015 . Phytochemicals and biological activities of Ruta chalepensis L. growing in Tunisia. Food Biosci. http://dx.doi.org/10.1016/j.fbio.2015.08.001.

Kaupp, U.B. 2010. Olfactory signalling in vertebrates and insects: differences and commonalities. Nat. Rev. Neurosci. 11, 188-200.

Landolt, P.J., Hofstetter, R.W. Biddick, L.L. 1999. Plant essential oil as arrestants and repellents for neonate larvae of the codling moth (Lepidoptera: Tortricidae). Environ. Entomol. 28, 954-960. 
Majdoub, O., Dhen, N., Souguir, S., Haouas, D., Baouandi, M., Laarif, A., Chaieb, I. 2014. Chemical composition of Ruta chalepensis essential oils and their insecticidal activity against Tribolium castaneum. Tunis J. Plant Prot. 9, 83-90.

Meccia, G., Rojas, L.B. Usubillaga, A. 2009. Estudio del aceite esencial de Ruta graveolens L. que crece en Estado Mérida, Venezuela. Rev Fac Farm. 50 (1), 7-9.

Mejri, J., Abderrabba, M., Mejri, M. 2010. Chemical composition of the essential oil of ruta chalepensis L: Influence of drying, hydro-distillation duration and plant parts. Ind Crop Prod. 32, 671-673.

Mejri, J., Bouajila, J., Sik Ali, S. B., Abderrabba, M.,Mejri, M. 2012. Ruta chalepensis L. Essential Oil: Chemical Composition and Phytotoxic Activity. JBAPN, 2, (6) 341-352.

Palma, R., Mutis, A., Manosalva, L., Ceballos, R., Quiroz, A. 2012. Behavioral and electrophysiological responses of Hylastinus obscurus to volatiles released from the roots of Trifolium pratense L. J. Soil Sci. Plant Nutr. 12 (1) $183-193$

Parra, L., Mutis, A., Ceballos, R., Lizama, M., Pardo, F., Perich, F. Quiroz, A. 2009. Volatiles released from Vaccinium corymbosum were attractive to Aegorhinus superciliosus (Coleoptera: Curculionidae) in a olfactometric bioassay. Environ. Entomol. 38, 781-789.

Rebolledo, R., Abarzúa, J., Zavala, A., Quiroz, A., Alvear, M. Aguilera, A. 2012. The effects of the essential oil and hydrolate of canelo (Drimys winteri) on adults of Aegorhinus superciliosus in the laboratory. Cien. Inv. Agr. 39, (3) $481-488$.

Regnault-Roger, C., Vincent, C., Arnason, J.T. 2012. Essential oils in insect control: low-risk products in a high-stakes world. Annu. Rev. Entomol. 57, 405-24.
Reyes, G. 1993. Aspectos morfológicos y biológicos de la especie Aegorhinus superciliosus (Coleoptera: Curculionidae). Tesis Ingeniero Agrónomo. Universidad Austral de Chile, Valdivia, Chile.

Sangwan, N.S., Farooqi, A.H.A., Shabih, F., Sangwan, R.S. 2001. Regulation of essential oil production in plants. Plant Growth Regul. 34, 3-21.

Stashenko, E.E., Acosta, R., Martínez, J.R. 2000. High-resolution gas-chromatographic analysis of the secondary metabolites obtained by subcriticalfluid extraction from Colombian rue (Ruta graveolens L.). J. Biochem. Biophys. Methods. 43, 379-390.

Szauman-Szumski, K.J, Peña, A, Kelly, D.R., Campos, M. 1998. Identification of $\mathrm{ch}$ e m i c a ls attractive to the olive bark beetle, Phloeotribus scarabaeoides, in laboratory bioassays. Bio Control. 43, 345-355.

Tabanca, N., Demirci, B., Kiyan, H.T., Ali, A., Bernier, U.R., Wedge, D.E., Khan, I.A., Başer, K.H.C. 2012. Repellent and Larvicidal Activity of Ruta graveolens essential oil and its major individual constituents against Aedes aegypti. Planta Med. 78-90.

Tampe, J., Parra, L., Huaiquil, K., Mutis, A., Quiroz, A. 2015. Repellent effect and metabolite volatiles profile of the essential oil of Achillea millefolium (Linnaeus) against Aegorhinus nodipennis (Hope) (Coleoptera: Curculionidae). Neotrop. Entomol. 44 (3): 279-285

Tounsi, M.S., Wannes, W.A., Ouerghemmi, I., Msaada, K., Smaoui, A., Marzouk, B. 2011. Variation in essential oil and fatty acid composition in different organs of cultivated and growing wild Ruta chalepensis L. Ind Crop Prod. 33, 617-623. 
Wang, Z., Ding, L., Li, T., Zhou, X., Wang, L., Zhang, H., Liu, L., Li, Y., Liu, Z., Wang, H., Zeng, H., He, H. 2005. Improved solvent-free microwave extraction of essential oil from dried Cuminum cyminum L. and Zanthoxylum bungeanum Maxim. J Chromatogr. A. 1091, 177-182.
Wakefield, M.E., Bryning, G.P., Collins, L.E., Chambers. J. 2005. Identification of attractive components of carob volatiles for the foreign grain beetle, Ahasverus advena (Coleoptera: Cucujidae). J. Stored Prod. Res. 41, 239-253. 